\title{
Ethical and legal implications for technological devices in clinical research in Europe
}

\author{
Flowchart design for ethical and legal decisions in clinical research \\ Ainara Garzo ${ }^{\dagger}$ \\ Neuroengineering Area \\ TECNALIA, Basque Research and Technology Alliance \\ (BRTA) \\ Donostia-San Sebastian, Spain \\ Nestor Garay-Vitoria \\ Computer Architecture and Technology Department \\ University of the Basque Country (UPV/EHU) \\ Donostia-San Sebastian, Spain \\ nestor.garay@ehu.eus
}

ainara.garzo@tecnalia.com

\begin{abstract}
In recent years engineers developing new technologies with assistive or medical purposes have become aware that to create acceptable and usable solutions they need to involve final users, patients and stakeholders in the design, development and evaluation of systems as well as in the device certification processes. Involving stakeholders in such processes has several ethical and legal implications. It has become evident that it is still difficult for engineers in Europe to know which ethical and legal processes should be carried out as they have not been previously trained in these issues during their studies.
\end{abstract}

This article is a review of the laws, standards and recommendations applicable in Europe concerning human involvement in new technologies research, with the aim of helping researchers in the region in question to identify the ethical and legal issues that could arise during those tasks. This review has been carried out in response to the identified need on the part of technological researchers.

The design of a flowchart is presented as a summary of the interpretation of the documentation reviewed with the aim of helping the researchers to take the ethical and legal decisions that apply to research involving humans.

The flowchart presented has been validated with various research projects in which the authors have participated. The proposed conceptual design can be used for taking decisions, but it is suggested that a tool based on this design be built with the aim of making decision taking easier for researchers in this area.

\section{*All authors contributed equally to this research \\ Corresponding author}

Permission to make digital or hard copies of part or all of this work for personal or classroom use is granted without fee provided that copies are not made or distributed for profit or commercial advantage and that copies bear this notice and the full citation on the first page. Copyrights for third-party components of this work must be honored. For all other uses, contact the Owner/Author.

Interacción '21, September 22-24, 2021, Málaga, Spain

(C) 2021 Copyright is held by the owner/author(s)

ACM ISBN 978-1-4503-7597-9/21/09.

https://doi.org/10.1145/3471391.3471403

\section{CCS CONCEPTS}

- Applied computing Health informatics • Social and professional topics $\sim$ Medical information policy $\cdot$ Humancentered computing $\sim$ User studies

\section{KEYWORDS}

User studies, informed consent, privacy, ethical committee, competent authority.

\section{ACM Reference format:}

Ainara Garzo and Nestor Garay-Vitoria. 2021. Ethical and legal implications for technological devices in clinical research in Europe: Flowchart design for ethical and legal decisions in clinical research. In XXI International Conference on Human Computer Interaction (Interacción '21), September 22-24, 2021, Málaga, Spain, 8 pages. https://doi.org/10.1145/3471391.3471403

\section{Introduction}

User involvement in design activities, such as software engineering, has been taking place for some time. The final user participation process in the design and evaluation of products can be found under different names such as, among others, Participatory Design, Contextual Design, User Centered Design (UCD), Human-Computer Interaction, Human-Factors, User eXperience or User Involvement [1]. Nowadays, considerable effort is being devoted to design and develop usable, well accepted, easy to use and ergonomic systems, processes and devices which relate to users' real needs. According to the ISO 9241 family, Human-Centered Design (HCD) is used instead of UCD, to refer to the stakeholders' involvement in the design and development of systems. The aim of this approach is to apply techniques that make the systems ergonomic and usable, which improve the productivity, accessibility and wellbeing and reduce stress and inherent risks [2]. Hence, HCD is a process and a set of techniques which are used in order to create new solutions, including products, services, spaces, organizations and ways of interaction $[3,4]$. The target users who are going to employ the new solution are at the center of the process. First, users' needs, wishes and behaviors are analyzed in order to find the desired 
outcomes. Once these are identified, possible solutions are designed taking feasibility and viability into account. It also has to be said that when medical devices are developed, especially if software is included, the harmonized norm 62366 relating to usability must be applied [5], thus HCD techniques are also very useful to ensure compliance with this norm.

The use of HCD techniques has several ethical implications, as mentioned by Garzo and Garay-Vitoria [6]. There are several recommendations regarding participants' involvement such as the Declaration of Helsinki [7] which has been used as a reference point in the scientific community in research with humans for many years or the Belmont report [8]. Moreover, the Oviedo convention document has been made an international legally binding instrument for the protection of humans in the biomedical field [9]. This agreement protects the rights and the dignity of humans with respect to biological and medical applications.

This work has been divided into the following tasks: 1) identify the need; 2) define the objectives and review the literature accordingly; 3) design a solution; 4) validate the solution. In the following lines, the motivation for the review is explained. Subsequently, a summary of the reviewed documents relating to the ethical and legal implications for stakeholder involvement has been drawn up. The design of a flowchart to solve the identified problem is proposed according to the previous conclusions, including a brief validation. Finally, we conclude with suggested future research lines and opportunities for this proposal.

\section{Problem identification}

Human involvement in the design and development of products and services has several ethical implications. Although some universities are aware of this and prepare the engineers on the ethical aspects involved before any research with humans takes place $[10,11]$, this is not usual nor mandatory in most European universities for engineers or researchers with a technological background. They are aware that technological developments require the involvement of humans in experiments, even more so in technological medical device design and development, but there are knowledge gaps concerning the ethical issues, and the documentation regarding this information is complex and spread out over several reports.

Other researchers also agree on the gap between ethics and human-centered practices, and some research has been done and proposals been made with regard to Artificial Intelligence technologies, for example [12]. Some European projects such as DIH-HERO [13], Satori [14], Inbots [15] or Wearable Robots [16], for example, have also been analyzing the ethical and legal issues as well as the necessary standards, best practices or recommendations to ensure the safety, security and ethical treatment of patients during the research.

In the DIH-HERO project a total of 43 semi-structured interviews were carried out with representatives from France, Germany, Italy, Poland, Serbia, Spain, Switzerland, the Netherlands and UK, in which 14 small and medium-sized enterprises also participated. The aim of those interviews was to collect information about the awareness and application of standards related to quality, safety, security, environmental care, ethical, legal and socio-economic issues, among others, related to health robotics. The conclusion was that interviewees considered that best practices in healthcare robotics were not yet well documented, collected, structured, harmonized or promoted. During this project, a flowchart was proposed to summarize the documentation applicable in each case, something which was welcomed by the participants.

\section{Review on ethical and legal implications}

Nowadays, it is well accepted that any research involving humans must be evaluated by an Institutional Review Board (IRB) or an ethical committee [17]. Any ethical committee activities will include at least the following ones [18]:

a) Evaluate the qualification of the principal investigator and research team, as well as the project feasibility;

b) Ensure that methodological, ethical and legal aspects and risks/benefits for the study are balanced;

c) Review that user data or samples can be properly traced, also taking into account additional regulations, such as Regulation 2016/679, also known as GDPR [19];

d) Develop good-practices and/or manage conflicts according to any applicable ethical principles;

e) Coordinate the activity with other boards;

f) Ensure the evaluated projects and personal data confidentiality.

However, additional ethical and legal issues must also be taken into account when humans are involved in research, as has been previously outlined by authors [6]. Additionally, in the Directive 93/42/CEE there is an important section about medical devices used in research with humans in which the technical specifications and the obligations of the researchers are detailed [20]. It is mentioned therein that any research must follow the recognized ethical principles and has to be approved by the corresponding ethical committee and also by the competent authority of the country in which the research will be carried out. The role of the competent authority is at least, to ensure that the medical device complies with the minimum safety specifications when used by or with a human, to evaluate the risks in order to know whether risks are offset by benefits for participants, and to evaluate whether the study is sufficiently relevant from a scientific point of view. Most countries of the European Union have their own competent authority [21]. The new Regulation $2017 / 745$ on medical devices came into effect repealing this Directive on May 2021 after some delay due to the impact of the COVID-19 pandemic [22,23]. In the case of the medical devices in research, both documents have some similarities, but the new Regulation reinforces the relevance of carrying out experimentation with medical devices before launching them on the market and then monitoring them when they are on the 
Ethical and legal implications for technological devices in clinical research in Europe

market. This Regulation also mentions the relevance of protecting vulnerable participants such us children, pregnant women, the elderly or immuno-compromised people, as the effects of the trials on these groups could be considered especially negative.

With respect to the obligatory nature of obtaining the endorsement from an Ethical Committee in order to carry out research with medical devices, Regulation 536/2014 relating to clinical tests with medication for human use can be found [24] This regulation came into effect in April 2016 in every member state of the European Union. Although its title may suggest that this Regulation is not applicable for this study, the same guidelines should be used while carrying out research with medical devices used by humans. In this case, the vulnerable groups are considered to be not only children or pregnant women, but also, any subject who might have problems to understand the research processes or very specific procedures involved in the clinical research. In those cases, a justification of the target group must be included, and an ethical evaluation would be mandatory according to this regulation.

In addition to the presented legislation, the harmonized standard ISO 14155 related to good clinical practice is a reference document [25]. This standard includes information regarding the ethical aspects that must be taken into account when designing a study, the need to obtain the ethical committee approval and the description of the requirements for this purpose, and the most appropriate informed consent process for the study. Other factors are also presented such as risk assessment, the data gathering notebook design, the researchers' manual, the monitoring of adverse effects, etc. moreover, several guidelines regarding the carrying out of these activities are given.

The International Conference on Harmonization should also be mentioned, which is a board regarding technical requirements for pharmacists to be applied in humans [26]. This group has developed several good clinical practice regulations that are recognized worldwide. The regulations were drawn up with clinical trials with drugs in mind, but almost all the recommendations should be applied in a similar way in any research with medical devices. Recommendations and laws also refer to rights to privacy and dignity, as these are considered as fundamental for humans.

The 95/46/CE European Directive has also been the point of reference in Europe in recent years with regard to personal data protection [27]. On the 25th of May of 2018 the new Regulation 2016/679 came into force repealing the named Directive and with the aim of unifying European personal data treatment and fostering the free movement of this data between the members of the European Union [19]. However, in the new Regulation, some sections may be subject to various changes depending on each member state. Some important issues relating to this Regulation have implications for personal data collection when participants take part in research. The new Regulation is also very sensitive with regard to personal data transfers to countries outside the European Union and in its Chapter V the restrictions concerning
Interacción '21, September 22-24, 2021, Málaga, Spain

that issue are explained, detailing that explicit consent must be requested for any data transfer after informing the subject of the possible risks thereof.

\subsection{Conclusions of the legal and ethical implications for research with humans}

A summary of the reviewed documentation is explained in the following lines:

- Participation in a research project must be voluntary, participants will be properly informed and may withdraw at any time without having to provide a reason.

- The risk-benefit must be balanced and correctly justified.

- Any research involving humans must be supervised by a competent and multidisciplinary entity to evaluate the related ethical considerations. That entity will be an ethical committee or an IRB. In the case that the research also involves a medical device, this must be notified to or approved by a competent authority.

- Vulnerable groups such as children, people with cognitive impairments, etc. should not take part in the research, unless the research is based on that target group. In that case, their participation will be properly justified and ethically supervised by an external group.

- The research results must be shared with the scientific community according to the best-practices on research, protecting the participants privacy.

- An informed consent process is mandatory for any research with humans which includes information regarding risks and benefits. Explicit consent, preferably written, will be requested from participants.

- In the case that a legal tutor is required in the informed consent process due to cognitive impairments or because children are involved, for example, the participant's acceptance must be also taken into account.

Regarding the personal data treatment, the summary of the applicable legislation is as follows:

- Do not record any personal data other than that which is strictly necessary.

- In the case that personal data treatment is necessary, consider the following points:

1. Record the minimum necessary for the required purpose.

2. Demonstrate that the subject affected has approved the data treatment. Accordingly, express consent will be needed.

- Informed consent related to data collection and treatment must include information about: 1) the data that will be collected and the purpose of its collection; 2) the data treatment controller and data protection officer; 3) the 
purposes of the treatment; 4) the legal basis for the processing; 5) the recipients of the personal data including third party countries or international organizations where applicable; 6) the envisaged time limits for erasure of the different categories of personal data; 7) the existence of the right to request the controller for access to, rectification and/or erasure of personal data and restriction of the personal data treatment; 8) the right to lodge a complaint with a supervisory authority.

- Any data collection for research purposes should: 1) respect fundamental rights and freedoms; 2) respect the principle of data minimization; 3) include pseudonymization to avoid personal identification when possible; 4) comply with other relevant legislation such as the existing legislation on clinical trials, if applicable; 5) protect the rights and freedoms of the data subject first, even if the data is of general interest.

- Member States may add some limitations over the Regulation relating to health, biometric or genetic, or scientific research data, such as in Spain [28] or Germany [29].

It was possible to find several proposals for the preparation of an informed consent document for any research involving humans [30-32]. As a summary of the reviewed documents and legislation it is recommended that the following information be included in this document:

1. A research summary including procedure information, objectives, benefits and the time that will be required of the participant.

2. Risks, discomforts or adverse events foreseen and the minimization measures.

3. Opportunity to be informed after participation.

4. Personal data treatment, including the time that the data will be stored as well as the information presented above.

5. Contact information of the research team, signature and date.

There must be sufficient information on the informed consent document to take the decision of whether to participate, and it must be written in understandable language according to the participants' capabilities [33].

A research procedure could be rejected by an ethical committee or IRB if risks and benefits are not balanced, the procedure or humans' participation is not well justified, or the methodology is not completely defined. In any case, the group who supervise the procedure will ask additional information and make some recommendations about the reviewed ethical considerations with the aim of helping the researchers to improve the procedure and enhance the participants' involvement.

\section{Conceptual design}

A flowchart has been designed with the aim of providing a tool which summarizes the regulations, norms and recommendations reviewed in this study (see Figure 1).

To build this concept design the process for the ethical and legal approvals needed in Spain, the UK, Germany, Denmark, Poland and Switzerland have been also included, as DIH-HERO project partners from those countries participated by facilitating the information corresponding to their countries. To apply the flowchart, first researchers have to indicate whether humans are involved in their study. Next, and depending on the characteristics of the study, several questions have to be answered in a given order and there are several possible outcomes:

a) Supervision by an ethical committee is not considered essential in the study when there is no personal data treatment, when humans are not directly involved in the trials, or when participants are not required to use any medical software or device, or when using any software or device, participants are not vulnerable and no risk (either physical, or psychological) is expected such as, for example, using a computer or a mobile phone for completing an anonymous survey. However, it is recommended that an ethical committee be contacted to clarify any doubt.

b) The study is considered a research project involving humans and therefore Ethical Committee approval is required in the case that personal data are being collected and/or managed and/or any device or software not considered a medical device is being used by the participants, or if participants are part of a vulnerable target group and/or if any risk (physical and/or psychological) is foreseen for the participants during the research.

c) The study is considered to be observational research and there is a need for Ethical Committee approval when humans are involved, medical devices and/or software that have $\mathrm{CE}$ markings are used and are going to be used according to the described instructions and the research follows the usual clinical practice.

d) Otherwise, the study is considered a clinical research which needs Ethical Committee approval, in addition to the approval or the notification (depending on the medical software or device characteristics, see Figure 1) of the competent authority. In all cases, the competent authority must be also informed about any relevant adverse events.

When humans or their personal data are involved in research, informed consent, which an Ethical Committee must supervise, is also needed. In the case that research with a medical device is performed (considered clinical research) registration in a public data-base is recommended, such as the World Health Organisation [34], U.S. National Library of Medicine [35], or Swiss National Clinical Trials Portal [36].

The letters ' $\mathrm{CE}$ ' that appear on the products mean they have been assessed to meet high safety, health, and environmental 
Ethical and legal implications for technological devices in clinical research in Europe

protection requirements. In the case of medical devices, the $\mathrm{CE}$ marking is the way in which a manufacturer indicates that a device conforms with the applicable requirements set out in Directive 93/42/CEE [20] and/or Regulation 2016/679 [19] concerning medical devices and other applicable Union harmonization legislation.

\section{Validation}

The presented flowchart (Figure 1) was designed according to the reviewed legislation and feedback received from the Spanish competent authority [37]. It has been applied in several research projects in which the authors have participated, and which involved human participation in technology evaluation. In this section some projects are presented as flowchart validation.
Interacción '21, September 22-24, 2021, Málaga, Spain

The aim of the Sentient project carried out within the FIK private financing program [38] was to develop a system which adapts the environment (temperature, lighting, sounds, ...) according to the user emotions defined by Ekman [39]. This type of system was identified as intrusive, and therefore to create an acceptable technology some exploratory focus groups and interviews were carried out with the elderly participants and their caregivers [40]. Participants' data were collected, and according to the flowchart, the supervision of an ethical committee was required. In this case, the Healthcare Ethical Committee from Ingema, the research center involved in the participants' recruitment, approved the methodology used $[40,41]$.

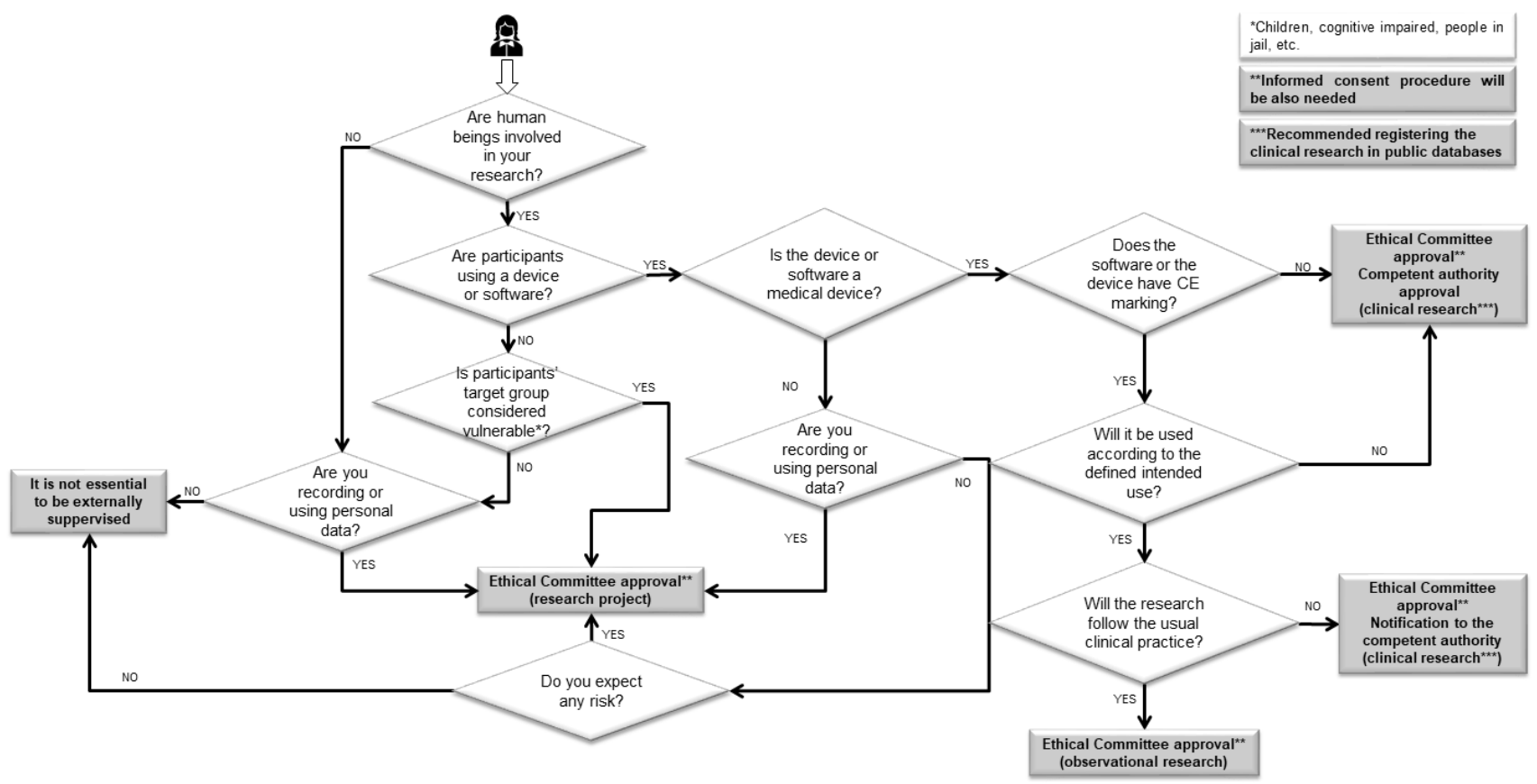

Figure 1: Flowchart to summarize the ethical and legal decisions for human involvement in technology evaluation according to existing laws and regulations in the European Union. 
The CogLaboration European project, was financed under the Seventh Framework European Programme [42]. A control law based on Dynamic Movement Primitives was implemented to control a robotic system composed of a robotic arm equipped with an anthropomorphic hand [43]. This control system was developed for industrial and home settings. The last set-up application was evaluated with a group of elderly people. Participants were requested to exchange different daily life objects with the robotic system and to fill in a questionnaire after the task [44]. In this project, humans were involved, and the device in use was under development. However, this device was not considered a medical device due to the defined intended use. During the trial, some personal data of the participants were recorded, and some risks were foreseen such as possible collisions or bumps between participants and the robot, which were avoided by ensuring a sufficient distance was maintained during the exchange. According to the flowchart, Ethical Committee approval was required, and in this case, the local Ethical Committee approved this experimentation.

The aim of the iFree project, locally financed through the ADINBERRI program [45], was to identify new ways to measure the frailty of the elderly using different technological systems including some DAVID Spine devices [46] and an Equimetrix prototype [47]. Several users, with different degrees of frailty participated to measure their balance using Equimetrix and their cervical and lumbar mobility and range of movement and strength using DAVID Spine Devices with the objective of matching the collected data with frailty status evaluated with standard scales. In this project the correlated data gathered in these devices has been used in order to identify the degree of frailty of future users. As Equimetrix is considered a medical device prototype, the corresponding ethical committee and competent authority approvals were requested prior to starting with participant recruitment, as outlined in the presented flowchart.

MERLIN is a project that has received funding from EIT Health ${ }^{1}$ [48]. In this project a clinical evaluation was carried out using the MERLIN system, which consists of the ArmAssist robotic system based on serious games, merged with the Antari Home Care telecare platform [49]. The system has been evaluated by 9 poststroke patients, at the Reina Sofia Hospital in Cordoba (Spain) [50] and by 12 patients at the University Medical Center in Groningen (The Netherlands) [51]. As the MERLIN system is considered a medical device prototype and thus did not have CE certification, the approval of the corresponding ethical committee and the competent authority was required, as stated on the presented flowchart. In this case, the approval was requested in both countries in which the trials were organized (Spain and the Netherlands) before starting patient recruitment.

\section{Discussion}

1 EIT Health is supported by the European Institute of Innovation and Technology (EIT), a body of the European Union receives support from the European Union's Horizon 2020 Research and innovation programme.
Proposed conceptual design aims to help researchers to take decisions on the ethical and legal approval needed to carry out any research involving humans in technological evaluations, including medical devices. This flowchart can be easily applied to research with technological devices involving humans. Before initiating human involvement, it is suggested that researchers answer the questions shown in the flowchart in Figure 1, in order to determine the ethical and legal approval needed in each case. The same approach used for the presented projects used for the flowchart validation could be used for any additional research.

The flowchart design presented has been validated with projects in which the authors have participated and it is set out in such a way as to have enough flexibility and validity to cope with future changes in the legislation, and to enhance researchers' understanding of the reviewed legislation.

In this review, it should be mentioned that one of the key issues in the new European Regulation on medical devices is to give greater importance to research with medical devices before they enter the market, as it has been found that there is a lack of studies of this kind. The Regulation also pretends to motivate the publication of the results in order to register and make traceable any study with medical devices.

\subsection{Limitations and future work}

The work presented has some limitations that must be mentioned. First, the concept design has only been validated in projects in which the authors had participated, thus it is mainly Spanish legislation which has been reviewed. Only in one of the cases could the applicable legislation in the Netherlands be validated. Thus, in future, additional validation for other European countries is proposed, which could be an onerous task due to the complexity of the different languages used around Europe.

Second, this work is only a concept design of a flowchart that could be used in decision taking. Several researchers have already used it and they were faced with some problems such as deciding if the device they were using was a medical device or not, how to check the CE marking, or the definition of intended use or usual clinical practice. However, no formal evaluation has been carried out. With the aim of addressing the aforementioned problems it was proposed to build a software prototype to help decision making in each case along with the recording of the corresponding information arising from evaluations involving humans.

\section{Conclusions and future work}

The present manuscript presents a flowchart as a summary of the analysis carried out regarding the recommendations, legislation and regulations within the European Union that apply to research with new technologies involving humans. 
Ethical and legal implications for technological devices in clinical research in Europe

This work also includes some recommendations for a research protocol description and informed consent process development, including personal data management.

The flowchart presented has been designed to address different researchers' needs, including the DIH-HERO partners and stakeholders. The flowchart was presented to the research community in a webinar organized by the DIH-HERO project consortium [52]. A tool has been also designed and built to help researchers understand and read the flowchart and, while doing so, resolve the identified problems [53]. This approach will help us to gather additional information regarding the usefulness and limitations of this conceptual design.

In the future, this flowchart will be updated in order to be used in several European countries, depending on their particular legislation.

\section{ACKNOWLEDGMENTS}

Special thanks to DIH-HERO partners for their help on the documentation interpretation for each country. The authors would also like to thank the volunteers who participated in the interviews.

This work was supported by the Department of Education, Universities and Research of the Basque Government (grantnumber IT980-16); and the DIH-HERO European project which has received funding from the European Union's Horizon 2020 research and innovation programme (grant-number 825003).

\section{REFERENCES}

[1] Jakob Nielsen. 1993. Usability Engineering. Morgan Kaufmann, San Francisco, CA.

[2] Ergonomics of human-system interaction - Part 220: Processes for enabling, executing and assessing human-centred design within organizations, ISO 9241-220:2019. Retrieved from http://iehf.org/ehf/wpcontent/uploads/2015/06/N1693_CD2_9241_220_2015-03.pdf

[3] IDEO.ORG. 2015. The Field Guide to Human-Centered Design. Retrieved from https://www.designkit.org/resources/1

[4] usability.gov. User-Centered Design Basics. Retrieved June 15, 2021 from https://www.usability.gov/what-and-why/user-centered-design.html

[5] Iso. 2015. IEC 62366-1:2015 Medical devices - Part 1: Application of usability engineering to medical devices. Retrieved from https://www.iso.org/standard/63179.html

Ainara Garzo and Nestor Garay-Vitoria. 2015. Ethical issues for user involvement in technological research projects: Directives and recommendations. In Contemporary Ethical Issues in Engineering, Stya Sundar Sethy (ed.). IGI Global, 251-269. DOI:https://doi.org/10.4018/9781-4666-8130-9.ch017

[7] WMA and World Medical Association. 2013. WMA Declaration of Helsinki - Ethical Principles for Scientific Requirements and Research Protocols. World Medical Association. Retrieved December 4, 2020 from https://www.wma.net/policies-post/wma-declaration-of-helsinkiethical-principles-for-medical-research-involving-human-subjects/

[8] The National Commission for the Protection of Humans Subjects of Biomedical and Behavioral Research. 1978. Belmont Report: Ethical Principles and Guidelines for the Protection of Human Subjects of Research, Report of the National Commission for the Protection of Human Subjects of Biomedical and Behavioral Research. U.S. Government Printing Office, Washington D.C.

Interacción '21, September 22-24, 2021, Málaga, Spain

Council of Europe. 1997. Convention for the Protection of Human Rights and Dignity of the Human Being with regard to the Application of Biology and Medicine: Convention on Human Rights and Biomedicine. Retrieved September 10, 2020 from https://www.coe.int/en/web/conventions/fulllist/-/conventions/treaty/164

UC Berkeley. 2020. CITI Training: Required Human Subjects Research Training for UC Berkeley Faculty, Staff, and Students. Human Research Protection Program. Education and Training. Retrieved December 1, 2020 from https://cphs.berkeley.edu/training.html

Eberhard Karls Universität Tübingen. 2020. Certificate "Ethics in practice." International Center for Ethics in the Sciences and Humanities (IZEW). Retrieved November 12, 2020 from https://unituebingen.de/en/facilities/central-institutions/international-center-forethics-in-the-sciences-and-humanities/teaching/ethics-in-practice/

Ben Shneiderman. 2020. Bridging the Gap Between Ethics and Practice: Guidelines for Reliable, Safe, and Trustworthy Human-centered AI Systems. ACM Trans. Interact. Intell. Syst. 10, 4 (2020), 1-31. DOI:https://doi.org/10.1145/3419764

DIH-HERO. DIH-HERO. Retrieved April 19, 2020 from https://dih-hero.eu

The Danish Board of Technology. Satori. Retrieved April 18, 2020 from https://satoriproject.eu/

INBOTS. 2020. INBOTS. Retrieved September 10, 2020 from http://inbots.eu

COST. European Cooperation in Science \& Technology. CA16116 Wearable Robots for Augmentation, Assistance or Substitution of Human Motor Functions. Retrieved June 15, 2021 from https://www.cost.eu/actions/CA16116/\#tabs\%7CName:overview

$\mathrm{M}^{\mathrm{a}}$ Jesús Marcos Muñoz and Mabel Marijuan. 2019. Investigación con personas fuera del ámbito sanitario: estudios de comportamiento psicología, ciencias del deporte y otros. ¿Cómo la evaluamos en los CEI? In VI Congreso ANCEI, Asociación Nacional de Comités de Ética de la Investigación (ANCEI), Tarragona, 39-41.

2007. Ley 14/2007, de 3 de julio, de Investigación biomédica. Madrid.

2016. Regulation (EU) 2016/679 of the European Parliament and of the Council of 27 April 2016 on the protection of natural persons with regard to the processing of personal data and on the free movement of such data, and repealing Directive 95/46/EC. Brussels. Retrieved from https://eurlex.europa.eu/eli/reg/2016/679/oj

1993. Directive 93/42/EEC of 14 June 1993 concerning medical devices. DOI:https://doi.org/2004R0726 - v.7 of 05.06 .2013

European Commission. Medical Devices - Sector. Contact Points of National Authorities. Retrieved June 15, 2021 from https://ec.europa.eu/health/sites/health/files/md_sector/docs/md_contac t_points_of_national_authorities.pdf

2017. Regulation (EU) 2017/745 of the European parliament and of the council of 5 April 2017 on medical devices, amending Directive 2001/83/EC, Regulation (EC) No 178/2002 and Regulation (EC) No 1223/2009 and repealing Council Directives 90/385/EEC and 93/42/EE. Estrasburg. DOI:https://doi.org/10.1080/21548331.1992.11705401

2020. Regulation 2020/561 of the European Parliament and of the Council of 23 April 2020 amending Regulation (EU) 2017/745 on medical devices, as regards the dates of application of certain of its provisions. Brussels. Retrieved from https:/eur-lex.europa.eu/legalcontent/EN/TXT/PDF/?uri=CELEX:32020R0561\&from=EN

20uncil of 16 April 2014 on clinical trials on medicinal products for human use, and repealing Directive 2001/20/EC. Strasbourg. Retrieved from http://eurlex.europa.eu/legal-

content/EN/TXT/PDF/?uri=OJ:JOL_2014_158_R_0001\&from=EN.

Accessed 14 July 2014.

ISO. 2011. ISO 14155:2011. Clinical investigation of medical devices for human subjects - Good clinical practice. Retrieved from https://www.iso.org/standard/45557.html

International Conference on Harmonisation of Technical Requirements for Registration of Pharmaceuticals for Human Use (ICH). 1996. ICH 


\section{Harmonised Tripartite Guideline for Good Clinical Practice E6(R1)}

27] 1995. Directive 95/46/EC of the European Parliament and of the Council of 24 October 1995 on the protection of individuals with regard to the processing of personal data and on the free movement of such data. Luxemburg. Retrieved from https:/eur-lex.europa.eu/legalcontent/EN/TXT/HTML/?uri=CELEX:31995L0046\&from=ES

[28] 2018. Ley Orgánica 3/2018, de 5 de diciembre, de Protección de Datos Personales y garantía de los derechos digitales. Jefatura del Estado, Madrid.

[29] Nikolaus Bertermann. 2020. Germany: Data Protection Laws and Regulations 2020. ICLG. Retrieved June 15, 2021 from https://iclg.com/practice-areas/data-protection-laws-andregulations/germany

[30] Mabel Marijuan, Begoña Lejona, Jon López de Heredia, Andoni Arcelay, Sagrario Martínez, Margarita Hernanz, Blanca Urkola, Amaya Hernando, and Olga Gabaldón. Guia práctica para la elaboracion de documentos de informacion y consentimiento. Osakidetza Servicio Vasco de Salud. Retrieved December $4, \quad 2020$ from http://cvb.ehu.es/open_course_ware/castellano/salud/bioetica/mcomple m/guia_cast.pdf

[31] CEISH. 2019. M10 - Memoria para el CEISH: Proyecto de investigación con seres humanos. Universidad del País Vasco (UPV-EHU). Retrieved June 15, 2021 from https://www.ehu.eus/es/web/ceid/ceish/formularios

[32] Insitutional Review Board. 2019. Investigator Manual. University of Colorado Boulder. Office of Research Integrity. Retrieved June 15, 2021 from https://www.colorado.edu/researchinnovation/irb/gettingstarted/investigator-manual

[33] WebAIM. 2020. Writing Clearly and Simply. Web accessibility in mind Retrieved June 15, 2021 from https://webaim.org/techniques/writing/

[34] World Health Organization. 2020. International Clinical Trials Registry Platform (ICRTRP). Retrieved June 15, 2021 from https://www.who.int/clinical-trials-registry-platform

[35] U.S. National Library of Medicine. 2020. ClinicalTrials.gov. Retrieved June 15, 2021 from https://clinicaltrials.gov/

[36] Federal Office of Public health (FOPH) and Federal Department of Home Affairs (FDHA). Swiss National Clinical Trials Portal (SNCTP Portal). Koordination Forschung am Menschen (kofam). Retrieved June 15, 2021 from https://www.kofam.ch/en/snctp-portal/

[37] Agencia Española de Medicamentos y Productos Sanitarios. Retrieved June 15, 2021 from https://www.aemps.gob.es

[38] TECNALIA. FIK: Tecnología para una vida mejor. Retrieved October 18 2020 from https://www.tecnalia.com/es/salud/fik-tecnologia-para-unavida-mejor/fik-tecnologia-para-una-vida-mejor.htm

[39] Paul Ekman. 1992. An Argument for Basic Emotions. Cogn. Emot. 6, 3/4 (1992), 169-200. Retrieved from http://www.paulekman.com/wpcontent/uploads/2009/02/Universality-Of-Emotional-Expression-Apersonal-History.pdf

[40] Ainara Garzo, Iraitz Montalbán, Enrique León, and Sara Schlatter. 2010. Sentient: An approach to Ambient Assisted Emotional Regulation. In International Symposium on Ambient Intelligence. Gimaraes, Portugal.

[41] Enrique León, Iraitz Montalban, and Ainara Garzo. 2011. Affective wellbeing supervision system and method. WO 2011/076243 A1. Retrieved June $15, \quad 2021 \quad$ from

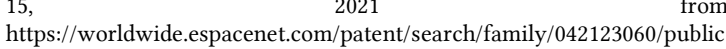
ation/WO2011076243A1?q=WO 2011\%2F076243 A1

[42] European Comission. 2017. CogLaboration. Successful Real World Human-Robot Collaboration: From the Cognition of Human-Human. cordis. Retrieved June 15, 2021 from https://cordis.europa.eu/project/id/287888/es

[43] Miguel Prada, Anthony Remazeilles, Ansgar Koene, and Satoshi Endo. 2013. Dynamic Movement Primitives for Human-Robot interaction: Comparison with human behavioral observation. In EEE/RSF International Conference on Intelligent Robots and Systems, Tokio, 1168-1175. DOI:https://doi.org/10.1109/IROS.2013.6696498

[44] Anthony Remazeilles, Miguel Prada, Ainara Garzo, Irati Rasines, Marco Controzzi, Christian Cipriani, Ilaria Strazzulla, Carlo Peccia, Joaquin
Canseco, Victor Fernandez-carbajales, Ana Belen Rodriguez, Alan M Wing, Elia Gatti, Mark Burgin, and Geoff Pegman. 2015. Towards HumanRobot object exchange lessons learned. In Science and System, RSS'15, workshop on Human-Robot handover. Roma.

[45] Diputación Foral de Gipuzkoa. Convocatoria de ayudas - Programa Adinberri. Retrieved June 15, 2021 from https://www.gipuzkoa.eus/es/etorkizunaeraikiz/programa-adinberri

[46] David Health Solutions Ltd. 2020. DAVID. Transforming muscoloskeletal care. Retrieved June 15, 2021 from https://www.davidhealth.com/

[47] Pierre Barralon. 2016. Method and system for functional balance assessment. Retrieved from https://worldwide.espacenet.com/patent/search/family/051900834/public ation/EP3017761A1?q=ep3017761A1

[48] EIT Health. MERLIN: Home-care arm rehabilitation. Retrieved June 15, 2021 from https://eithealth.eu/project/merlin/

[49] Ainara Garzo, Javier Arcas Ruiz-Ruano, Iñigo Dorronsoro, Gabrie Gaminde, Je Hyung Jung, Javier Téllez, and Thierry Keller. 2020. MERLIN: upper-limb rehabilitation robot system for home environment. In Converging Clinical and Engineering Research on Neurorehabilitation IV. IProceedings of the 5th International Conference on Neurorehabilitation (ICNR2020), Springer. Retrieved from https://www.springer.com/gp/book/9783030703158\#aboutBook

[50] Silvia Guillén-Climent, Ainara Garzo, Maria Nieves Muñoz-Alcaraz Pablo Casado-Adam, Javier Arcas Ruiz-Ruano, Manuela Mejías-Ruiz, and Fernando Jesús Mayordomo-Riera. 2021. A usability study in patients with stroke using MERLIN, a robotic system based on serious games for upper limb rehabilitation in the home setting. F. Neuroeng. Rehabil. 18, 41 (2021). DOI:https://doi.org/https://doi.org/10.1186/s12984-021-00837-z

[51] S.G. Rozevink, C.K. van der Sluis, A. Garzo, T. Keller, and J.M. Hijmans. 2021. HoMEcare aRm rehabiLItatioN (MERLIN): telerehabilitation using an unactuated device based on serious games improves the upper limb function in chronic stroke. F. Neuroeng. Rehabil. 18, 48 (2021). DOI:https://doi.org/https://doi.org/10.1186/s12984-021-00841-3

[52] DIH-HERO. 2021. Webinar - Introduction to healthcare robotics for robotics companies. Retrieved June 10, 2021 from https://dih hero.eu/event/webinar-introduction-to-healthcare-robotics-for-roboticscompanies/

[53] DIH-HERO. 2021. Guidance tool - Robotic devices evaluation with human beings. Retrieved June 10, 2021 from https://dih-hero.eu/ethics-tool/ 